Portland State University

PDXScholar

Environmental Science and Management

Faculty Publications and Presentations

$11-2015$

\title{
Increased Taxonomic and Functional Similarity Does Not Increase the Trophic Similarity of Communities
}

\author{
Thomas K. Pool \\ Centre National de la Recherche Scientifique \\ Julien Cucherousset \\ Centre National de la Recherche Scientifique \\ Stéphanie Boulêtreau \\ Centre National de la Recherche Scientifique \\ Sébastien Villéger \\ Université de Montpellier \\ Angela L. Strecker \\ Portland State University, angela.strecker@wwu.edu
}

See next page for additional authors

Follow this and additional works at: https://pdxscholar.library.pdx.edu/esm_fac

Part of the Environmental Indicators and Impact Assessment Commons, Environmental Monitoring

Commons, and the Natural Resources and Conservation Commons

Let us know how access to this document benefits you.

\begin{abstract}
Citation Details
Pool, T. K., Cucherousset, J., Boulêtreau, S., Villéger, S., Strecker, A. L., \& Grenouillet, G. (2015). Increased Taxonomic and Functional Similarity Does Not Increase the Trophic Similarity of Communities. Global Ecology and Biogeography, 25(1), 46-54.
\end{abstract}

This Post-Print is brought to you for free and open access. It has been accepted for inclusion in Environmental Science and Management Faculty Publications and Presentations by an authorized administrator of PDXScholar. Please contact us if we can make this document more accessible: pdxscholar@pdx.edu. 


\section{Authors}

Thomas K. Pool, Julien Cucherousset, Stéphanie Boulêtreau, Sébastien Villéger, Angela L. Strecker, and Gaël Grenouillet 
Title: Increased taxonomic and functional similarity does not increase communities' trophic similarity

Thomas K. Pool*,1,2 (phone: +33 (0) 5615573 84; e-mail: thomas.pool@univ-tlse3.fr) Julien Cucherousset ${ }^{1,2}$ (phone: +33 (0) 5615584 61; e-mail: julien.cucherousset@univtlse3.fr)

Stéphanie Boulêtreau ${ }^{1,2}$ (phone: +33(0)5 615573 48; e-mail:

stephanie.bouletreau@univ-tlse3.fr)

Sébastien Villéger ${ }^{3}$ (phone: +33 (0) 46747 32; email: sebastien.villeger@univ-montp2.fr)

Angela L. Strecker ${ }^{4}$ (phone: +1 503725 2427; e-mail: strecker@pdx.edu)

Gaël Grenouillet ${ }^{1,2}$ (phone: +33 (0) 5615569 11; e-mail: gael.grenouillet@univ-tlse3.fr)

${ }^{1}$ Université Toulouse 3 Paul Sabatier, Centre National de la Recherche Scientifique (CNRS), Ecole Nationale de Formation Agronomique (ENFA) ;UMR5174 Laboratoire Évolution \& Diversité Biologique (EDB); 118 route de Narbonne, F-31062 Toulouse, France.

${ }^{2}$ CNRS, Université Paul Sabatier; UMR5174 EDB, F-31062 Toulouse, France

${ }^{3}$ CNRS, Laboratoire Biodiversité Marine et ses usages (MARBEC), Université de Montpellier, 34095 Montpellier, France

${ }^{4}$ Department of Environmental Science and Management, Portland State University, Portland, OR, USA

Running title: Functional vs. trophic diversity similarity

${ }^{*}$ Corresponding author: Thomas K. Pool, UPS, UMR5174, Laboratoire Évolution et

Diversité Biologique (EDB), Université de Toulouse, 31062 Toulouse, France. (phone:

05.61.55.73.84; e-mail: thomas.pool@univ-tlse3.fr)

Word count: 3,635 main text

Reference count: 45 general references 


\section{ABSTRACT}

33 1. Aim Despite a long-standing research interest in the association between communities'

34 biodiversity (i.e. taxonomic and functional composition) and trophic structure, our understanding of the relationship remains limited. Community assembly theory predicts

36 that niche partitioning will result in communities with a diverse array of functional traits,

37 which in turn, may facilitate a correspondingly diverse array of trophic interactions that

38 define those communities' trophic niche. The aim of our study is to test this prediction.

2. Location North America

3. Methods We built a database composed of functional traits and stable isotope values

$41\left(\delta^{13} \mathrm{C}\right.$ and $\left.\delta^{15} \mathrm{~N}\right)$ for 63 freshwater fish communities containing 109 species in 34 lentic and

4229 lotic ecosystems. First, we tested whether communities' taxonomic diversity was

43 positively associated with their functional diversity and if communities' functional

44 diversity was positively associated with their trophic diversity using linear mixed models

45 (i.e. alpha diversity approach). Second, we assessed communities' taxonomic, functional

46 and trophic similarity using multiple regression on distance matrices (MRM) and their

47 respective 'turnover' and 'nestedness-resultant' components to test if communities'

48 taxonomic similarity was positively correlated with their functional similarity and if

49 communities' functional similarity was positively associated with their trophic similarity

50 (i.e. beta diversity approach).

51 4. Results We found that communities' functional diversity increased as taxonomic

52 diversity increased. Similarly, communities' trophic diversity increased as functional

53 diversity increased. The pairwise taxonomic and functional similarity of communities were 
54 also positively associated but there was a weak relationship between communities'

55 functional and trophic similarities.

56 5. Main conclusions Our study demonstrates that communities with similar functional

57 characteristics can have disparate food web structures suggesting that additional site

58 specific factors influence community variation in trophic niche geometry. Determining the

59 relative importance of functional characteristics and site-specific factors in shaping trophic

60 interactions is crucial to better understand how future species loss and species

61 introductions will affect food web structure and ecosystem functioning.

62 6. Keywords Functional and trophic diversity, alpha and beta diversity, compositional

63 similarity. 
A time-integrated assessment of species relationships and energy flow within ecosystems can be quantified using stable isotopes, identifying the ecological scaffolding that forms communities' trophic structure (Fry, 2006; Layman et al., 2012). Employing a stable isotopic approach has provided valuable insight into trophic processes such as omnivory (Thompson et al., 2007), ontogenetic dietary shifts (Freedman et al., 2011), and resource partitioning (Esteves \& Lobón-Cerviá, 2001) while also demonstrating that food web structure is linked to the functioning and stability of ecosystems (Thompson et al., 2012). Despite these advances, substantial gaps in our knowledge of community assembly remain regarding how a community's taxonomic and functional composition is linked to its trophic

74 architecture. For example, the extent that species will consistently fill similar 'roles' (i.e. more closely linked to communities' functional diversity than their taxonomic diversity (Petchey \& Gaston, 2006). This is because communities' functional traits are reflections of the biological, ecological and physiological constraints made in response to the temporal 
87 and spatial variations in environmental conditions, competition for resources, and predation (i.e. the functional niche; Winemiller, 2005). While previous studies examining various aspects of communities' functional diversity have assisted with providing mechanistic links between species compositions and the critical factors that influence specific systems (e.g. Poff, 1997; Pool et al., 2010; Suding et al., 2008), our ability to predict remains largely untested.

Trophic ecology studies typically investigate the trophic diversity of individual communities (i.e. alpha diversity approach; Layman et al., 2012) or a small number of communities. Alternatively, variation in trophic diversity between communities can be assessed (i.e. beta diversity approach), as is commonly performed in taxonomic and

105 influence from site-specific factors.

In the present study, we aimed to untangle the complex relationships between 
processes associated with nutrient cycling (e.g. Vanni, 2002) and primary productivity (e.g.

111 Schindler et al., 1997). Furthermore, fishes are suitable for our study because they are an

112 incredibly diverse and multi-trophic group of aquatic species occupying a wide array of

113 trophic roles within food webs ranging from strictly herbivorous grazers to apex predators.

114 First, we assessed the relationship between taxonomic, functional, and trophic diversity

115 (defined here as niche size) within communities (i.e. alpha diversity approach). We

116 predicted that individual community's taxonomic and functional diversity would positively

117 correlate along with their functional and trophic diversity. Second, we investigated the

118 pairwise similarity of communities (i.e. beta diversity approach) and predicted that

119 communities' taxonomic similarity would positively correlate with communities' functional

120 similarity along with their functional and trophic similarity. These predictions are based on

121 niche partitioning theory (McKane et al., 2002) predicting that, as competition for

122 resources between species within a community increases, species tend to have a more

123 diverse array of biological and ecological traits, which in turn, results in a wider spectrum

124 of resource use and a larger trophic niche. Here, lentic and lotic freshwater ecosystems

125 were tested independently to study the association between community composition and

126 trophic structure within and between ecosystems at the continental scale.

128 METHODS

129 Community selection

130 Candidate fish communities were identified using a multi-tiered data collection approach 131 utilizing primary scientific articles, comprehensive texts of regional fish faunas, university 132 reports, and online databases. The search was restricted to North America because a 
133 wealth of studies containing functional and trophic (i.e. stable isotopes) data on freshwater

134 fishes are available for this region (Cucherousset et al., 2012; Frimpong \& Angermeier,

135 2012). First, we identified 58 studies that provided averaged species stable isotope values

$136\left(\delta^{13} \mathrm{C}\right.$ and $\left.\delta^{15} \mathrm{~N}\right)$ in 176 fish communities. In some studies, several communities were

137 identified in the same ecosystem but were designated as separate fish communities

138 because sampling events varied spatially (i.e. sampling different areas along a drainage) or

139 temporally (i.e. sampling an area during different years). Second, data for 12 biological and

140 ecological traits (i.e. behavioural, life history, morphological, and diet) were collected to

141 characterize the functional attributes of the species within each community (Frimpong \&

142 Angermeier, 2012; Froese \& Pauly, 2012; Appendix S1 in Supporting Information). These

143 attributes were selected because they characterize the main dimensions of species

144 ecological niches and are commonly used in fish functional diversity studies (Winemiller \&

145 Rose, 1992; Olden et al., 2008). If greater than two trait values were unknown for a species

146 it was excluded and subsequently, every candidate community containing that species was

147 removed from the database. Third, in an attempt to include only communities that had

148 been comprehensively sampled (i.e. avoiding studies targeting specific species), a

149 minimum richness threshold criterion of five species was set for inclusion in the database.

150 To validate this multi-tiered approach, the corresponding authors for each study were

151 contacted to determine if all the fish species collected during their field sampling were

152 analyzed for stable isotopes. The authors ( 16 of the 18 who responded) indicated that

153 every species collected in sufficient numbers (i.e. enough individuals to estimate a realistic

154 average of stable isotope values; $\mathrm{n} \geq 5$ ) was analyzed for stable isotopes, demonstrating our

155 data can be considered an accurate estimation of the fish communities' taxonomic, 
156 functional and trophic diversity. Certainly, rare species may not have been identified in

157 some of our source studies because they are challenging to capture in sufficient numbers to

158 appropriately estimate their stable isotope values. In communities that had rare species

159 with unique trait profiles (i.e. top predators or detritivores) differing from more abundant

160 species, the diversity of those fish communities may have been underrepresented.

161 The final database contained 23 studies and included 63 freshwater fish

162 communities (lentic: $n=34$ and lotic: $n=29$ ) composed of 109 species occurring

163 throughout North America (ranging from Florida, USA, to Nunavut Territory, Canada and

164 from Washington State, USA to Maine, USA; Appendix S2 in Supporting Information). This

165 final database utilized in our analyses is a subset of a larger database constructed to study

166 the isotopic structure of fish communities at a global scale (Sagouis et al., 2015).

168 Data analyses

169 Taxonomic diversity

170 The scientific name of each species was confirmed using Fishbase (Froese \& Pauly, 2012),

171 permitting the cross-referencing of community composition lists. 'Taxonomic diversity' was

172 calculated as the number of species within each community.

174 Functional diversity

175 For most species, functional trait values were assigned based on research conducted in

176 North America capturing the natural variation for each species in this region. Whenever

177 possible, continuous trait values were used (e.g. body length, fecundity) but some traits

178 required the use of discrete trait categories (e.g. reproductive guild, primary spawning 
179 season). In a few instances, $\leq 2$ trait values were unknown ( 4 of 109 species) and were 180 treated as missing values in the subsequent analyses. The 'functional diversity' of each 181 community was calculated by standardizing trait values and then creating a dissimilarity 182 matrix using Gower's distance, a metric able to accommodate nominal, ordinal, continuous, 183 and missing data (Pavoine et al., 2009). Then, a principal coordinate analysis (PCoA) on this 184 functional distance matrix was computed to construct a multidimensional functional space 185 (Villéger et al., 2008). The first three principal coordinate axes explained a significant 186 proportion (75.5 \%) of the total variation in trait matrix (i.e. $29.0 \%, 26.1 \%$, and $20.4 \%$, 187 respectively) based on the randomized broken-stick method and $\alpha=0.05$ (Jackson, 1993). 188 Those trait-based principal coordinate scores, along with the species-by-community 189 matrix, were then used to measure each community's functional diversity calculated as the 190 'minimum convex hull volume' using the Quickhull algorithm (Villéger et al., 2008). More 191 simply, the functional diversity of each community was quantified as the volume created by 192 a group of trait-based points, each representing a fish species. A second trait matrix was also created retaining only behavioural, morphological, 194 and trophic traits to calculate an additional functional diversity value for each community. 195 This reduced trait matrix was created to determine if the results from our full trait matrix 196 analyses were simply an artefact of the particularly wide breadth of selected traits. The 197 functional diversity values generated from the reduced trait matrix were utilized in parallel 198 with our full trait matrix values in subsequent analyses. 
201 The 'trophic diversity' was quantified in each community using the 'convex hull metric'

202 based the averaged $\delta^{13} \mathrm{C}$ and $\delta^{15} \mathrm{~N}$ values of each species (Layman et al., $2007 \& 2012$ ). This

203 conservative metric was selected because it is the most analogous to our functional

204 diversity approach. The convex hull quantified the minimum area encompassing species

205 stable isotope values within each community (Layman et al., 2007).

207 Statistical analyses

208 Community composition

209 The relationships between the taxonomic, functional, and trophic alpha diversity of fish 210 communities were tested with linear mixed models using article ID as a random variable 211 since, in many cases (19 of 24 studies), more than one community was reported from the 212 same source article (Borenstein et al., 2010). The appropriate transformation parameter

213 for each response variable was identified using the statistical estimation method known as

214 the maximum likelihood approach developed by Box and Cox (1964). First, functional

215 diversity (Box-Cox transformed with $\lambda=0.22$ ) was used as a response variable and

216 taxonomic diversity as a fixed predictor. Second, trophic diversity (log-transformed) was

217 used as a response variable and functional diversity as a fixed predictor. All models were 218 run separately for lentic and lotic ecosystems.

\section{Community similarity}

221 The pairwise taxonomic beta diversity of communities was measured using Jaccard's

222 dissimilarity index, i.e. percentage of species not shared by communities compared to the 223 total number of species. To quantify functional beta diversity, convex hulls for each 
224 community were used to measure the pairwise functional dissimilarity between

225 communities likewise using the Jaccard's index (Villéger et al., 2008). In an effort to use an

226 approach analogous to our taxonomic and functional analyses, the trophic beta diversity of

227 communities was quantified using a stable isotope 'centroid' approach that aligns the

228 stable isotope convex hull centroids for each community pairing (Schmidt et al., 2011;

229 Appendix S3 in Supporting Information). The centroid of each community was calculated as

230 the mean $\delta^{13} \mathrm{C}$ and $\delta^{15} \mathrm{~N}$ species value (Schmidt et al., 2011). This approach maximizes the

231 trophic hull overlap between communities as they share the same centroid values,

232 providing a conservative assessment of trophic niche dissimilarity.

To evaluate the relationships between taxonomic, functional and trophic beta

234 diversity, we used multiple regression on distance matrices (MRM; Lichstein, 2007). MRM

235 is utilized to study ecological data involving multiple regression of a response matrix on

236 any number of explanatory distance or similarity matrices. For our MRM analyses, spatial

237 dissimilarity was calculated as the Euclidean distance between communities. A

238 randomization was used to test for differences between beta diversity types ( $\mathrm{n}=4999$

239 permutations) and $R^{2}$ values were used when there were multiple significant predictor

240 variables (Peres-Neto et al., 2006). While this approach has been criticized for

241 underestimating explained variance (Legendre et al., 2005), we used it primarily as a

242 comparative tool to test for differences between communities' taxonomic and functional

243 beta diversity as well as communities' functional and trophic beta diversity. Using this

244 approach also permitted variance partitioning to be used examining the independent

245 effects of our predictor variables and geographic space. 
Finally, to identify underlying patterns in community structure, taxonomic beta

247 dissimilarity was deconstructed into 'turnover' (i.e. species replacement between

248 communities) and 'nestedness-resultant' (i.e. difference in the number of species between

249 communities) components (Baselga et al., 2012). This provided insight because high

250 taxonomic dissimilarity (i.e. high beta diversity) can be driven by taxonomic turnover (no

251 species in common) or nestedness (one community is a subset of the other). For the

252 functional and trophic beta diversity analyses, we also identified the turnover and

253 nestedness-resultant components (Villéger et al., 2013). In-step with our community

254 composition analyses, all community similarity analyses were run separately for lentic and

255 lotic ecosystems. Statistical analyses were conducted in R 2.15.1 using the ape, betapart,

256 cluster, ecodist, FD, geometry, and vegan libraries (R Development Core Team, 2012).

257

258 RESULTS

259 Community composition

260 The taxonomic diversity of fish communities ranged from 5 to 19 species in lentic

261 ecosystems and from 5 to 14 species in lotic ecosystems. The functional diversity of fish

262 communities was strongly influenced by species behavioural, life history, and

263 morphological traits, positively contributing to the first principal coordinate axes scores

264 with minimal contributions of traits linked to diet (Appendix S1). As predicted, the

265 functional diversity of fish communities significantly increased as taxonomic diversity

266 increased irrespective of the ecosystem type (lentic: $p<0.001$ and lotic: $p<0.001$; Table 1;

267 Fig. 1a). Communities' functional and trophic diversity were significantly and positively 
268 correlated in lentic ecosystems ( $p=0.039$; Table 1; Fig. 1b) and were marginally and 269 positively correlated in lotic ecosystems ( $p=0.064$; Table 1; Fig. 1b).

271 Community similarity

272 Lentic communities' taxonomic beta diversity was positively correlated with functional 273 beta diversity using $\operatorname{MRM}\left(R^{2}=0.421, p<0.01\right)$ and variance partitioning with greater

274 variation uniquely explained by the taxonomic predictor $\left(R^{2}=0.257\right)$ than geographic 275 space $\left(R^{2}=0.053\right)$. Similarly, lotic communities' taxonomic beta diversity positively 276 correlated with functional beta diversity $\left(R^{2}=0.207, p<0.01\right)$ with greater variation 277 uniquely explained by the taxonomic predictor $\left(R^{2}=0.142\right)$ than geographic space $\left(R^{2}=\right.$ 278 0.050). Thus, within lentic and lotic ecosystems, pairs of communities that tended to be 279 similar taxonomically also tended to be similar functionally (Fig. 2a).

In contrast, lentic communities' functional beta diversity had a weak correlation 281 with trophic beta diversity using MRM $\left(R^{2}=0.093, p<0.01\right)$ and variance partitioning with 282 greater variation uniquely explained by the functional predictor $\left(R^{2}=0.092\right)$ than 283 geographic space $\left(R^{2}=0.001\right)$. Lotic communities' functional beta diversity similarly had a 284 weak correlation with trophic beta diversity $\left(R^{2}=0.026, p<0.01\right)$ with low variation 285 uniquely explained by both the functional predictor $\left(R^{2}=0.010\right)$ and geographic space $\left(R^{2}\right.$ $286=0.011$ ). A weak correlation also existed between communities' functional and trophic beta 287 diversity in lentic and lotic systems when the reduced trait dataset was used albeit with 288 slightly stronger correlations between beta diversity types (Appendix S4). Ultimately, 289 within lentic and lotic ecosystems, pairs of communities that tended to be similar 290 functionally did not tend to be similar trophically (Fig. 2b). 
Finally, the mean compositional dissimilarity of communities' taxonomic and

292 functional diversity was higher than occurred for communities' trophic diversity (Table 2).

293 The variation within communities' taxonomic and functional diversity was primarily driven

294 by compositional turnover (Table 2). In contrast, variation within the trophic beta diversity

295 for community pairings was driven by relatively equal contributions from the turnover and 296 nestedness-resultant components (Table 2). These results were consistent in both lentic 297 and lotic ecosystems.

298

299 DISCUSSION

In this study, we found a positive relationship between individual fish community's

301 taxonomic and functional diversity along with their functional and trophic diversity within

302 both lentic and lotic ecosystems. In contrast, while communities' pairwise taxonomic

303 similarity was positively associated with their functional similarity, we demonstrated that

304 increased functional similarity of communities did not consistently increase their trophic

305 similarity. This suggests that increased likeness of communities' trait composition does not

306 necessarily result in more similar trophic structures. Taken together these results

307 demonstrate that the relationship between taxonomic, functional, and trophic diversity is

308 complex with a communities' trophic diversity driven, to some extent, by the

309 characteristics of species within that community but also by system-specific factors

310 influencing the architecture of trophic interactions.

311 The idiosyncratic association between communities' functional and trophic diversity

312 may be attributable to the high contribution of behavioural and life history traits in the

313 calculation of fish communities' functional diversity. While the incorporation of non- 
314 trophic traits to compute the functional diversity of communities unequivocally has value

315 when attempting to assess the complete ecological niche of a community, our results

316 display that not all traits contribute equally to trophic structure. Given that some species

317 traits will be more closely linked than others to food web structure and possibly also

318 ecosystem processes, modification of specific aspects of communities' functional profile

319 (i.e. a reduction in the breadth of trophic guild types) may be of particular conservation

320 concern. For example, communities could display minimal change in their functional

321 diversity (quantified from a diverse array of trait types) and still exhibit substantial shifts

322 in their trophic structure over time. However, even with the removal of life history traits

323 from our analyses believed to poorly contribute to defining communities' trophic structure,

324 the weak association between communities' functional and trophic similarity remained.

325 Ultimately while the trait composition of a community mechanistically links those species

326 to their environment, claims that alteration of a communities' functional composition will

327 redefine its trophic structure may not consistently be substantiated.

328 The weak association between communities' functional and trophic similarity may

329 have also occurred because static trait values were used to quantify functional diversity.

330 This approach, commonly used in ecology, fails to account for species variance in the

331 expression of traits (i.e. intra- and inter- population trait plasticity) associated with biotic

332 or abiotic factors within diverse environments. In contrast, stable isotope analyses

333 represent an integrative approach that accounts for the direct and indirect interactions

334 occurring in a community (Layman et al., 2012, Cucherousset et al., 2012) and is therefore

335 highly sensitive to specific interactions between species. Accounting for traits intraspecific

336 variation along environmental gradients instead of using species mean trait values could 
337 more clearly identify the mechanisms by which communities' functional diversity

338 influences trophic interactions (Ackerly \& Cornwell, 2007). Furthermore, associations

339 between communities' functional and trophic similarity may have been difficult to assess

340 because functionally specialized species can exhibit behavioural opportunism within some

341 systems to utilize available resources (Bellwood et al., 2006). Functionally generalized

342 species may alternatively exhibit focused or specialized feeding behaviour obscuring a

343 clear association between communities' functional and trophic diversity (Bellwood et al.,

344 2006). Such functional plasticity is known to occur within fish species in association with

345 their life-history stage and dynamic factors such as local environmental variation (Simpson

346 et al., 2010; Zhao et al., 2014). A significant forthcoming challenge in ecology will be to

347 properly incorporate this intraspecific and interspecific trait variation into the study of

348 multiple animal groups (i.e. aquatic insects, reptiles, and fish) at the population and

349 community levels.

Several abiotic and biotic factors may have also influenced the site-specific trophic

351 structure of fish communities such as nutrient availability (Jeppesen et al., 2000), habitat

352 heterogeneity (Layman et al., 2007), ecosystem size (Post et al., 2000), human disturbance

353 (Freedman et al., 2013), and non-native species introduction (Cucherousset et al., 2012).

354 Additionally, communities' trophic structure may have been influenced by assembly

355 history, i.e. the sequence of species lost or gained over time (Fukami et al., 2010). For

356 instance, Stier et al. (2013) demonstrated that the timing of arrival for carnivorous coral

357 reef fish (Paracirrhites arcatus) to natural reefs influenced the assembly of the prey fish

358 community. Therefore, historical variation in the composition of communities (i.e. species

359 colonisation, introduction and extirpation) along with other site-specific factors may 
account for contemporary discontinuities in pairwise comparisons of communities' trophic diversity.

As expected working at a large macroecological scale (i.e. continental scale), the mean taxonomic, functional, an trophic dissimilarity of communities was relatively high; principally associated with high turnover indicating minimal overlap in their taxonomic and functional compositions. Interestingly, even when calculating communities' trophic beta diversity by aligning their isotope centroids, turnover remained a substantial contributor to the total compositional dissimilarities between communities suggesting highly variable trophic structures. For example, some communities that contained almost identical species profiles, and in turn similar functional compositions, had very different isotopic values resulting in different "trophic niche" shapes. These results further validate that fish trophic structures are highly variable, potentially providing unique information about the functioning of local communities and ecosystems.

There is broad consensus that increased taxonomic and functional diversity within communities assists with maintaining ecosystems stability and resilience (Hooper et al., 2005) but it has been challenging to identify how variation in individual communities' composition is linked to the functionality of those ecosystems. Our results indicate that exploring how communities' trophic structure is linked to ecosystem functioning may be a particularly informative thread of research to pursue given the variation in trophic structure we observed. Indeed, Poisot et al. (2013) found that the structure of trophic interactions within food webs (i.e. trophic complementarity) effectively predicted ecosystem functioning in complex modeled communities. Additionally, with the preservation of ecosystem processes becoming an increasingly emphasized conservation 
383 goal, it should be recognized that systems with similar taxonomic or functional profiles 384 might have unique trophic structures potentially driving system specific functionality. As 385 additional work is done to study compositional changes over time beyond characterizing 386 fish communities, analyses should also assess if the trophic structure of communities is

387 becoming more similar given that our results suggest that processes such as taxonomic or 388 functional homogenization might induce 'trophic homogenization' in only certain 389 circumstances.

391 ACKNOWLEDGEMENTS

392 EDB is part of the "Laboratoire d'Excellence" (LABEX) entitled TULIP (ANR-10-LABX-41).

393 Funding support was provided by the French National Agency for Water and Aquatic 394 Environment (Onema) (Convention Onema-EDB 2011-2013) and an "ERG Marie Curie" 395 grant (PERG08-GA-2010-276969). We graciously acknowledge all the authors of the 396 source data that responded to our inquiry for details associated with their field sampling 397 and data analysis. 


\section{REFERENCES}

Ackerly, D.D. \& Cornwell, W.K. (2007) A trait-based approach to community assembly: partitioning of species trait values into within- and among-community components. Ecology Letters, 10, 135-145.

Baselga, A., Lobo, J.M., Svenning, J.-C., Aragón, P. \& Araújo, M.B. (2012) Dispersal ability modulates the strength of the latitudinal richness gradient in European beetles. Global Ecology and Biogeography, 21, 1106-1113.

Bellwood, D.R., Wainwright, P.C., Fulton, C.J. \& Hoey, A.S. (2006) Functional versatility supports coral reef biodiversity. Proceedings of the Royal Society of London Series B: Biological Sciences, 273, 101-107.

Borenstein, M., Hedges, L. V, Higgins, J.P.T. \& Rothstein, H.R. (2010) A basic introduction to fixed-effect and random-effects models for meta-analysis. Research Synthesis Methods, 1, 97-111.

Box, G.E.P. \& Cox, D.R. (1964) An analysis of transformations. Journal of the Royal Statistical Society, Series B, 26, 211-252.

Cucherousset, J., Boulêtreau, S., Martino, A., Roussel, J.M. \& Santoul, F. (2012) Using stable isotope analyses to determine the ecological effects of non-native fishes. Fisheries Management and Ecology, 19, 111-119.

Esteves, K.E. \& Lobón-Cerviá, J. (2001) Composition and trophic structure of a fish community of a clear water Atlantic rainforest stream in southeastern Brazil. Environmental Biology of Fishes, 62, 429-440.

Freedman, J.A., Carline, R.F. \& Stauffer, J.R. (2013) Gravel dredging alters diversity and structure of riverine fish assemblages. Freshwater Biology, 58, 261-274. 
421 Freedman, J.A., Curry, R.A. \& Munkittrick, K.R. (2011) Stable isotope analysis reveals

422

423

424

425

426

427

428

429

430

431

432

433

434

435

436

437

438

439

440

441

442

anthropogenic effects on fish assemblages in a temperate reservoir. River Research and Applications, 28, 1804-1819.

Frimpong, E.M. \& Angermeier, P.L. (2012) FishTraits Database. Available at: http://www.fishtraits.info (accessed on March 2014).

Froese, R. \& Pauly, D. (2012) FishBase. Available at: http://www.fishbase.org (accessed on February 2014).

Fry, B. (2006) Stable Isotope Ecology. Springer Publishing, New York, USA.

Fukami, T., Dickie, I.A, Paula Wilkie, J., Paulus, B.C., Park, D., Roberts, A., et al. (2010) Assembly history dictates ecosystem functioning: evidence from wood decomposer communities. Ecology Letters, 13, 675-684.

Hooper, D.U., Chapin, F.S., Ewel, J.J., Hector, A., Inchausti, P. \& Lavorel, S. (2005) Effects of biodiversity on ecosystem functioning: a consensus of current knowledge. Ecological Monographs, 75, 3-35.

Jackson, D.A. (1993) Stopping rules in principal components analysis: a comparison of heuristic and statistical approaches. Ecology, 74, 2204-2214.

Jeppesen, E., Jensen, J.P., Søndergaard, M., Lauridsen, T. \& Landkildehus, F. (2000) Trophic structure, species richness and biodiversity in Danish lakes: changes along a phosphorus gradient. Freshwater Biology, 45, 201-218.

Layman, C.A., Araujo, M.S., Boucek, R., Harrison, E., Jud, Z.R., Matich, P., et al. (2012) Applying stable isotopes to examine food-web structure: an overview of analytical tools. Biological Reviews, 87, 545-562. 
Layman, C.A., Quattrochi, J.P., Peyer, C.M. \& Allgeier, J.E. (2007) Niche width collapse in a resilient top predator following ecosystem fragmentation. Ecology Letters, 10, 937944.

Legendre, P., Borcard, D. \& Peres-Neto, P.R. (2005) Analyzing beta diversity: partitioning the spatial variation of community composition data. Ecological Monographs, 75, 435450.

Lichstein, J. (2007) Multiple regression on distance matrices: a multivariate spatial analysis tool. Plant Ecology, 188, 117-131.

McKane, R.B., Johnson, L.C., Shaver, G.R., Nadelhoffer, K.J., Rastetter, E.B., Fry, B., et al. (2002) Resource-based niches provide a basis for plant species diversity and dominance in arctic tundra. Nature, 415, 68-71.

Olden, J.D., Poff, N.L. \& Bestgen, K.R. (2008) Trait synergisms and the rarity, extirpation, and extinction risk of desert fishes. Ecology, 89, 847-856.

Pavoine, S., Vallet, J., Dufour, A.B., Gachet, S. \& Daniel, H. (2009) On the challenge of treating various types of variables: application for improving the measurement of functional diversity. Oikos, 118, 391-402.

Peres-Neto, P.R., Legendre, P., Dray, S. \& Borcard, D. (2006) Variation partitioning of species data matrices: estimation and comparison of fractions. Ecology, 87, 26142625.

Petchey, O.L. \& Gaston, K.J. (2006) Functional diversity: back to basics and looking forward. Ecology Letters, 9, 741-758. 
464 Poff, N.L. (1997) Stream ecology landscape filters and species traits: towards mechanistic understanding and prediction in stream ecology. The North American Benthological Society, 16, 391-409.

467 Poisot, T., Mouquet, N. \& Gravel, D. (2013) Trophic complementarity drives the 468 469

Post, D.M., Pace, M.L. \& Hairston, N.G. (2000) Ecosystem size determines food-chain length in lakes. Nature, 405, 1047-1049.

R Development Core Team. (2012) R: a language and environment for statistical computing. R Foundation for Statistical Computing, Vienna, Austria. Available at: http://www.r-project.org/.

Sagouis, A., Cucherousset, J., Villéger, S., Santoul, F. \& Boulêtreau, S. (2015) Non-native species modify the isotopic structure of freshwater fish communities across the globe. Ecography, (in press).

Schindler, D.E., Carpenter, S.R., Cole, J.J., Kitchell, J.F. \& Pace, M.L. (1997) Influence of food web structure on carbon exchange between lakes and the atmosphere. Science, 277, $248-251$.

Schmidt, S.N., Harvey, C.J. \& Vander Zanden, M.J. (2011) Historical and contemporary trophic niche partitioning among Laurentian Great Lakes coregonines. Ecological Applications, 21, 888-896. 
Simpson, S.D., Meekan, M.G., Larsen, N.J., McCauley, R.D. \& Jeffs, A. (2010) Behavioral plasticity in larval reef fish: orientation is influenced by recent acoustic experiences. Behavioral Ecology, 21, 1098-1105.

Stier, A.C., Geange, S.W., Hanson, K.M. \& Bolker, B.M. (2013) Predator density and timing of arrival affect reef fish community assembly. Ecology, 94, 1057-1068.

Suding, K.N., Lavorel, S., Chapin, F.S., Cornelissen, J.H.C., Díaz, S., Garnier, E., et al. (2008) Scaling environmental change through the community-level: a trait-based responseand-effect framework for plants. Global Change Biology, 14, 1125-1140.

Thompson, R.M., Brose, U., Dunne, J.A, Hall, R.O., Hladyz, S., Kitching, R.L., et al. (2012) Food webs: reconciling the structure and function of biodiversity. Trends in Ecology \& Evolution, 27, 689-697.

Thompson, R.M., Hemberg, M., Starzomski, B.M. \& Shurin, J.B. (2007) Trophic levels and trophic tangles: the prevalence of omnivory in real food webs. Ecology, 88, 612-617.

Vanni, M.J. (2002) Nutrient recycling by animals in freshwater ecosystems. Annual Review of Ecology, Evolution, and Systematics, 33, 341-370.

Villéger, S., Grenouillet, G. \& Brosse, S. (2013) Decomposing functional $\beta$-diversity reveals that low functional $\beta$-diversity is driven by low functional turnover in European fish assemblages. Global Ecology and Biogeography, 22, 671- 681.

Villéger, S., Mason, N.W.H. \& Mouillot, D. (2008) New multidimensional functional diversity indices for a multifaceted framework in functional ecology. Ecology, 89, 2290-2301.

Whittaker, R.H. (1960) Vegetation of the Siskiyou mountians, Oregon and California. Ecological Monographs, 30, 279-338. 
509 Winemiller, K.O. (2005) Life history strategies, population, regulation, and implications for 510 fisheries management. Canadian Journal of Fisheries and Aquatic Sciences, 62, 872511885.

512 Winemiller, K.O. \& Rose, K.A. (1992) Patterns of life-history diversification in North 513 American fishes: implications for population regulation. Canadian Journal of Fisheries $514 \quad$ and Aquatic Sciences, 49, 2196-2218.

515 Zhao, T., Villeger, S., Lek, S. \& Cucherousset, J. (2014) High intraspecific variability in the 516 functional niche of a predator is associated with ontogenetic shift and individual $517 \quad$ specialization. Ecology and Evolution, 4, 4649-4657.

518 


\section{SUPPLIMENTARY MATERIAL TITLES}

520 Appendix S1 A list of the 12 functional traits used to characterize the functional diversity

521 of each species.

522 Appendix S2 Map of North America displaying the location of each fish community

523 included in the analyses.

524 Appendix S3 A conceptual framework displaying the 'centroid' trophic beta diversity

525 approach.

526 Appendix S4 Results from the multiple regression on distance matrices (MRM) analyses

527 using a reduced total of 7 traits.

528 


\section{DATA SOURCES USED IN THIS STUDY}

\section{Lentic source references}

Campbell, L.M., Thacker, R., Barton, D., Muir, D.C.G., Greenwood, D. \& Hecky, R.E. (2009) Reengineering the eastern Lake Erie littoral food web: The trophic function of nonindigenous Ponto-Caspian species. Journal of Great Lakes Research, 35, 224-231.

Chumchal, M.M. \& Hambright, K.D. (2009) Ecological factors regulating mercury contamination of fish from Caddo Lake, Texas, U.S.A. Society of Environmental toxicology and chemistry, 28, 962-72.

Clarke, L.R., Vidergar, D.T. \& Bennett, D.H. (2005) Stable isotopes and gut content show diet overlap among native and introduced piscivores in a large oligotrophic lake. Ecology of Freshwater Fish, 14, 267-277.

Croteau, M., Luoma, S.N. \& Stewart, A.R. (2005) Trophic transfer of metals along freshwater food webs: evidence of Cadmium biomagnification in nature. American Society of Limnology and Oceanography, 50, 1511-1519.

Freedman, J.A. (2005) Movement patterns and trophic structure of a reservoir fish community assessed using stable isotope analysis. Thesis, The University of New Brunswick.

Freedman, J.A., Curry, R.A. \& Munkittrick, K.R. (2012) Stable isotope analysis reveals anthropogenic effects on fish assemblages in a temperate reservoir. River Research and Applications, 28, 1804-1819.

Johnston, T.A., Keir, M. \& Power, M. (2010) Response of Native and Naturalized Fish to Salmonid Cage Culture Farms in Northern Lake Huron, Canada. Transactions of the American Fisheries Society, 139, 660-670. 
552 Keough, J.R., Sierszen, M.E., Hagley, C.A., Keough, R. \& Hagley, A. (1996) Analysis of a Lake

553 Superior coastal food web with stable isotope techniques. Limnology and

$554 \quad$ Oceanography, 41, 136-146.

555 Kidd, K.A., Schindler, D.W., Hesslein, R.H. \& Muir, D.C. (1998) Effects of trophic position and

556 lipid on organochlorine concentrations in fishes from subarctic lakes in Yukon

557 Territory. Canadian Journal of Fisheries and Aquatic Sciences, 55, 869-881.

558 Overman, N.C., Beauchamp, D. a., Berge, H.B., Mazur, M.M. \& McIntyre, J.K. (2009) Differing

$559 \quad$ Forage Fish Assemblages Influence Trophic Structure in Neighboring Urban Lakes.

$560 \quad$ Transactions of the American Fisheries Society, 138, 741-755.

561 Sanders, T., Biddanda, B., Stricker, C. \& Nold, S. (2011) Benthic macroinvertebrate and fish

562 communities in Lake Huron are linked to submerged groundwater vents. Aquatic

563 Biology, 12, 1-11.

564 Schoen, E.R. \& Beauchamp, D.A. (2010) Predation impacts of lake trout and Chinook salmon

565 in Lake Chelan, Washington : Implications for prey species and fisheries management.

$566 \quad$ U.S. Geological Survey report \#WACFWRU-010-01, pp.1-84.

567 Swanson, H.K., Kidd, KA. \& Reist, J.D. (2010) Effects of Partially Anadromous Arctic Charr

568 (Salvelinus alpinus) Populations on Ecology of Coastal Arctic Lakes. Ecosystems, 13,

$569 \quad 261-274$.

570 Vander Zanden, M.J., Chandra, S., Allen, B.C., Reuter, J.E. \& Goldman, C.R. (2003). Historical

571 Food Web Structure and Restoration of Native Aquatic Communities in the Lake Tahoe

572 (California-Nevada) Basin. Ecosystems, 6, 274-288.

573 Zhang, L., Campbell, L.M. \& Johnson, T.B. (2012) Seasonal variation in mercury and food

574 web biomagnification in Lake Ontario, Canada. Environmental Pollution, 161, 178-84. 
Lotic source references

577 Chasar, L.C., Scudder, B.C., Bell, A.H., Wentz, D.A. \& Brigham, M.E. (2008) Total Mercury, 578 Methylmercury, and Carbon and Nitrogen stable isotope data for biota from selected streams in Oregon, Wisconsin, and Florida, 2002-04. U.S. Geological Survey Report Data Series, 349, pp.1-20.

Delong, M.D., Thorp, J.H., Greenwood, K.S. \& Miller, M.C. (2001) Responses of consumers and food resources to a high magnitude, unpredicted flood in the upper Mississippi River basin. Regulated Rivers: Research \& Management, 17, 217-234.

Eitzmann, J.L. \& Paukert, C.P. (2009) Urbanization in a Great Plains river: effects on fishes and food webs. River Research and Applications, 26, 948-959.

Gido, K.B., Franssen, N.R. \& Propst, D.L. (2006) Spatial Variation in $\delta 15 N$ and $\delta 13 C$ Isotopes in the San Juan River, New Mexico and Utah: Implications for the Conservation of Native Fishes. Environmental Biology of Fishes, 75, 197-207.

Herwig, B.R., Soluk, D.A., Dettmers, J.M. \& Wahl, D.H. (2004) Trophic structure and energy flow in backwater lakes of two large floodplain rivers assessed using stable isotopes.

592 Herwig, B.R., Wahl, D.H., Dettmers, J.M. \& Soluk, D.A. (2007) Spatial and temporal patterns 593 in the food web structure of a large floodplain river assessed using stable isotopes. Canadian Journal of Fisheries and Aquatic Sciences, 22, 12-22. Canadian Journal of Fisheries and Aquatic Sciences, 508, 495-508. on the food web of boreal rivers. River Research and Applications, 974, 962-974. 
597 Pilger, T.J., Gido, K.B. \& Propst, D.L. (2010) Diet and trophic niche overlap of native and 598 nonnative fishes in the Gila River, USA: implications for native fish conservation. $599 \quad$ Ecology of Freshwater Fish, 19, 300-321. 
TABLES

601 Table 1 Results of the linear mixed models used to test for the relationships between

602 taxonomic, functional and trophic alpha diversity for communities in lentic $(\mathrm{n}=34)$ and

603 lotic $(n=29)$ ecosystems in North America. Given are the model degrees of freedom (df),

604 model estimates with standard errors (SE), and $p$-values $(p)$.

\begin{tabular}{llllll}
\hline \multicolumn{2}{l}{ Taxonomic vs Functional Alpha Diversity } & & & \\
Parameter & Source of variation & Ecosystem type & df & Estimate (SE) & $\boldsymbol{p}$-value \\
\hline FunD & TaxD & Lentic & 19 & $0.07(0.01)$ & $<0.001$ \\
& Intercept & Lentic & 19 & $0.65(0.11)$ & $<0.001$ \\
\multirow{2}{*}{ FunD } & TaxD & Lotic & 20 & $0.11(0.01)$ & $<0.001$ \\
& Intercept & Lotic & 20 & $0.27(0.11)$ & 0.024
\end{tabular}

Functional vs Trophic Alpha Diversity

\begin{tabular}{lllclc} 
Parameter & Source of variation & Ecosystem type & df & Estimate (SE) & p-value \\
\hline \multirow{2}{*}{ TroD } & FunD & Lentic & 19 & $0.10(0.04)$ & $<0.039$ \\
& Intercept & Lentic & 19 & $1.80(0.23)$ & $<0.001$ \\
\multirow{2}{*}{ TroD } & FunD & Lotic & 20 & $0.08(0.04)$ & 0.064 \\
& Intercept & Lotic & 20 & $1.40(0.21)$ & $<0.001$ \\
\hline
\end{tabular}

605 TaxD, Taxonomic alpha diversity: FunD, Functional alpha diversity; TroD, Trophic alpha 606 diversity; SE, Standard error

607 
608 Table 2 Summary table of the taxonomic, functional, and trophic beta diversity of fish

609 community pairs with the turnover and nestedness-resultant components of each type of

610 beta diversity in lentic ( $\mathrm{n}=560$ pairs $)$ and lotic ( $\mathrm{n}=399$ pairs $)$ ecosystems.

\begin{tabular}{lllll}
\hline & $\begin{array}{l}\text { Ecosystem } \\
\text { type }\end{array}$ & Taxonomic & Functional & Trophic \\
\hline $\begin{array}{llll}\text { Beta } \\
\text { diversity }\end{array}$ & Lentic & $0.85 \pm 0.21$ & $0.84 \pm 0.16$ & $0.61 \pm 0.15$ \\
& Lotic & $(0-1)$ & $(0-1)$ & $(0.22-0.90)$ \\
& & $0.86 \pm 0.22$ & $0.85 \pm 0.21$ & $0.66 \pm 0.14$ \\
Turnover & Lentic & $(0-1)$ & $(0-1)$ & $(0.27-0.95)$ \\
& & $0.81 \pm 0.26$ & $0.61 \pm 0.32$ & $0.29 \pm 0.21$ \\
& Lotic & $0.84 \pm 0.25$ & $(0-1)$ & $(0-0.89)$ \\
Nestedness- & Lentic & $(0-1)$ & $(0-1)$ & $0.26 \pm 0.21$ \\
resultant & & $0.04 \pm 0.07$ & $0.23 \pm 0.22$ & $0.32 \pm 0.25$ \\
& Lotic & $(0-0.42)$ & $(0-0.97)$ & $(0-0.89)$ \\
& & $0.02 \pm 0.06$ & $0.25 \pm 0.27$ & $0.39 \pm 0.27$ \\
& $(0-0.38)$ & $(0-0.86)$ & $(0.01-0.95)$ \\
\hline
\end{tabular}

611 The mean \pm standard deviation and range (in parentheses) are presented. 


\section{FIGURE LEGEND}

613 Fig. 1 Relationships between communities' (a) taxonomic and functional and (b) functional

614 and trophic alpha diversity in lentic $(n=34)$ and lotic $(n=29)$ ecosystems. Solid lines show

615 the best-fitting linear mixed regressions after Box-Cox transformations of dependent

616 variables. See Table 1 for the linear mixed model results (estimates and p-values)

617 associated with the relationships between alpha diversity types. The functional diversity

618 was transformed with $\lambda=0.22\left({ }^{*}\right)$ and trophic diversity was log transformed $\left(^{* *}\right.$ ).

619

620 Fig. 2 Relationships between fish communities' (a) taxonomic and functional and (b)

621 functional and trophic beta diversity within lentic and lotic ecosystems. See the results

622 associated with the multiple regression on distance matrices (MRM) for the statistical

623 significance of the beta diversity relationships represented here.

624 


\section{FIGURES}

626 Fig. 1
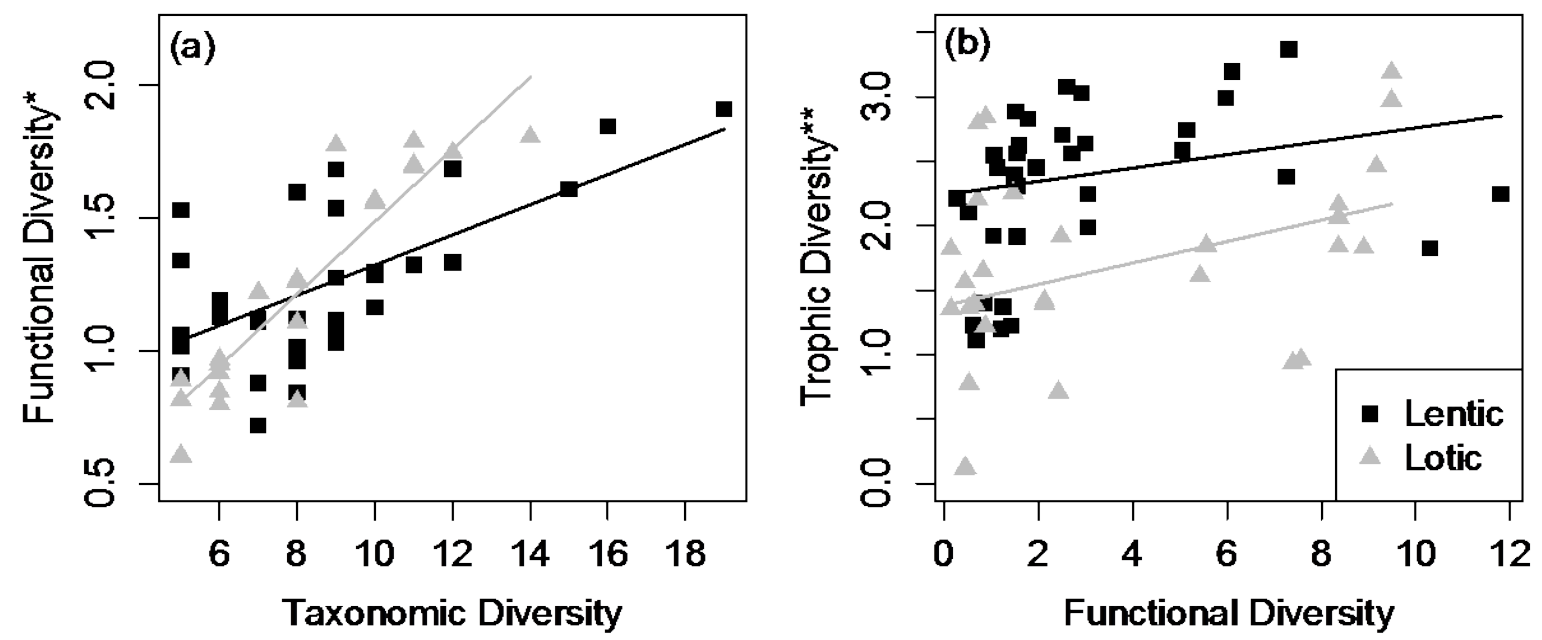

627 
Fig. 2
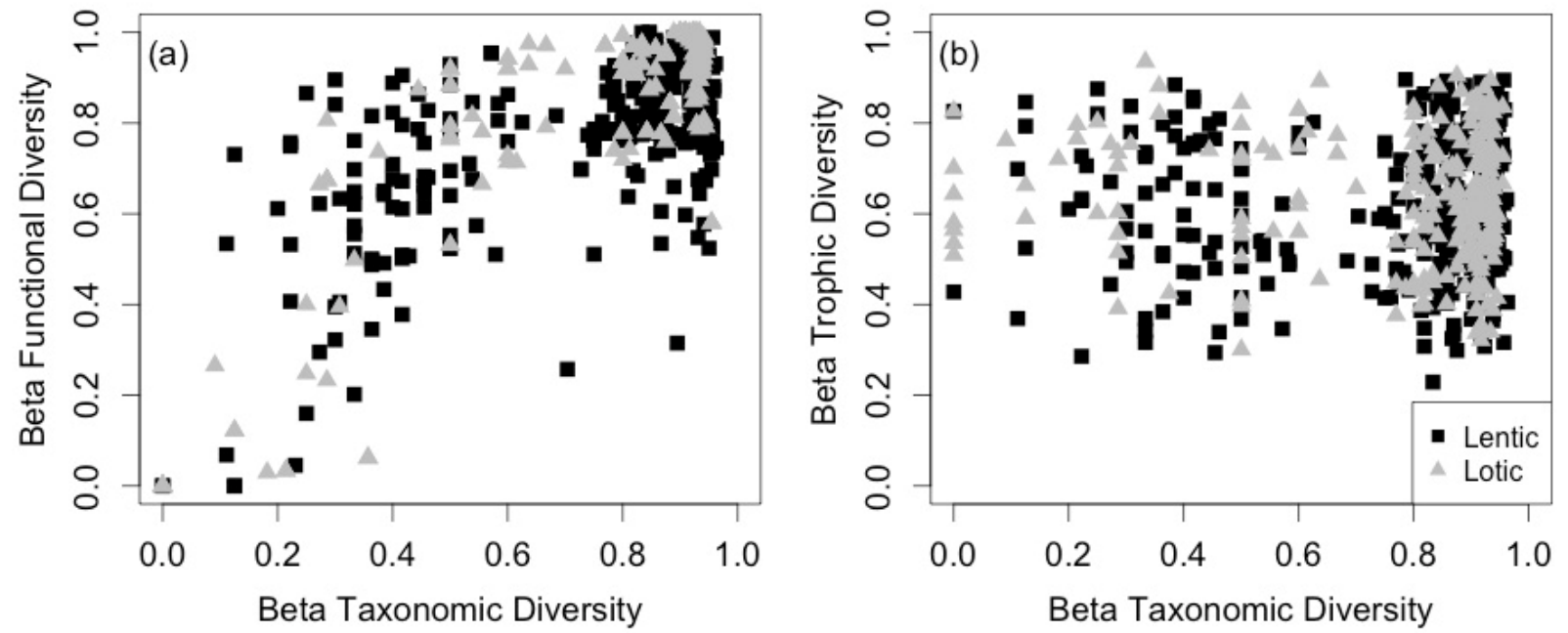

629

630 


\section{SUPPORTING INFORMATION}

633 Appendix $\mathbf{S 1}$ List of the 12 functional traits used to characterize the functional diversity of

634 each species with the loadings for the first three principal coordinate axes (PCs); the axes

635 utilized to calculate the functional diversity of each fish community.

\begin{tabular}{|c|c|c|c|c|c|}
\hline Category & Trait & Description and (or) units & $P C 1$ & $P C 2$ & $P C 3$ \\
\hline \multirow[t]{4}{*}{ Behavior } & $\begin{array}{l}\text { Substrate } \\
\text { preference }\end{array}$ & $\begin{array}{l}\text { Vegetation, mud-silt-sand, cobble- } \\
\text { boulder, or generalist. }\end{array}$ & -0.187 & 0.849 & 0.130 \\
\hline & $\begin{array}{l}\text { Fluvial } \\
\text { dependence }\end{array}$ & $\begin{array}{l}\text { Slow, moderate, or fast current } \\
\text { velocity. }\end{array}$ & 0.411 & -0.984 & 0.030 \\
\hline & Vertical position & $\begin{array}{l}\text { Benthic, surface and water } \\
\text { column, or generalist. }\end{array}$ & 0.570 & 1.966 & 0.055 \\
\hline & Potandromous & $\begin{array}{l}\text { Requiring movement through } \\
\text { fresh water systems to complete } \\
\text { their life cycle (binary). }\end{array}$ & 1.528 & -0.018 & 0.621 \\
\hline \multirow[t]{5}{*}{ Life history } & Longevity & $\begin{array}{l}\text { Maximum potential life span } \\
\text { (years) }\end{array}$ & 1.006 & -0.328 & -0.092 \\
\hline & $\begin{array}{l}\text { Age at } \\
\text { maturation }\end{array}$ & Age at maturation (years) & 1.506 & -0.415 & -0.489 \\
\hline & Fecundity & $\begin{array}{l}\text { Total number of eggs or offspring } \\
\text { per breeding season }\end{array}$ & 0.536 & 0.061 & -0.420 \\
\hline & $\begin{array}{l}\text { Primary } \\
\text { spawning season }\end{array}$ & $\begin{array}{l}\text { Fall (Sept-Nov), winter (Dec-Feb), } \\
\text { spring (March-May), summer } \\
\text { (June-Aug). }\end{array}$ & 1.016 & 0.324 & 0.089 \\
\hline & $\begin{array}{l}\text { Reproductive } \\
\text { guild }\end{array}$ & $\begin{array}{l}\text { Non-guarders (open substratum), } \\
\text { non-guarders (brood hiders), } \\
\text { guarders (substratum choosers), } \\
\text { guarders (nest spawners), } \\
\text { substratum indifferent. }\end{array}$ & -1.260 & 0.848 & 0.551 \\
\hline Morphology & $\begin{array}{l}\text { Maximum total } \\
\text { body length }\end{array}$ & Maximum total body length $(\mathrm{cm})$ & 1.444 & 0.004 & -0.092 \\
\hline \multirow[t]{2}{*}{ Trophic } & Trophic breadth & $\begin{array}{l}\text { Count of encompassing categories } \\
\text { (herbivore, planktavore, } \\
\text { invertivore, picivore, and } \\
\text { detritivore). }\end{array}$ & -0.175 & 0.407 & -1.902 \\
\hline & Trophic guild & $\begin{array}{l}\text { Herbivore, plankton-invertivore, } \\
\text { invertivore, invertivore-piscivore, } \\
\text { piscivore, or generalist. }\end{array}$ & 0.205 & 0.310 & -1.915 \\
\hline
\end{tabular}


638 Appendix S2 Map of North America displaying the location of each lentic ( $\mathrm{n}=34 ; \boldsymbol{\square})$ and

639 lotic $(\mathrm{n}=29 ; \boldsymbol{\Delta})$ community included in our analysis. Study references for each community 640 are listed below.

641

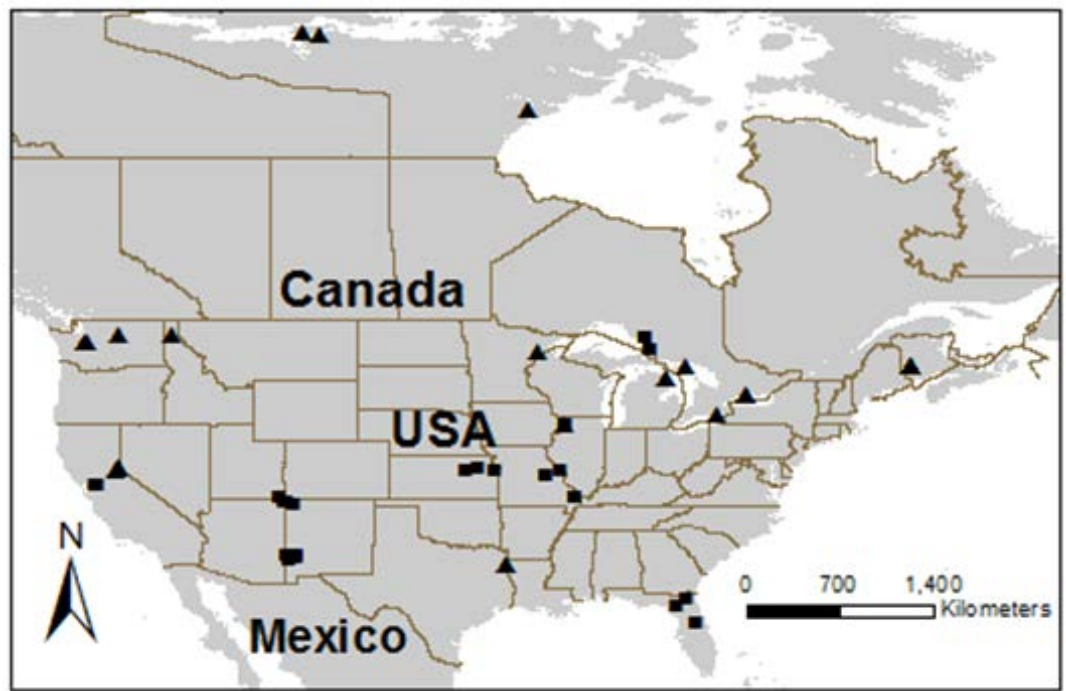

642 
643 Appendix S3 Conceptual framework displaying a (a) classical Venn diagram illustrating

644 the beta diversity for two communities. Beta diversity identifies, in the case of trophic

645 diversity, the change in 'trophic space' occupied by two communities. In each model, part B

646 and part $\mathrm{C}$ identifies unique trophic area occupied by each community and part $\mathrm{A}$ identifies

647 shared trophic area occupied by both communities. (b) In the 'centroid' trophic beta

648 diversity approach, the convex hull centroids of the two communities are aligned (Schmidt 649 et al. 2011).

650

(a)

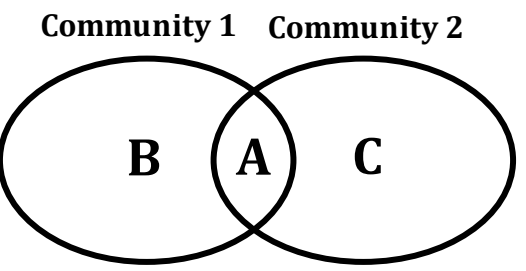

651

(b)

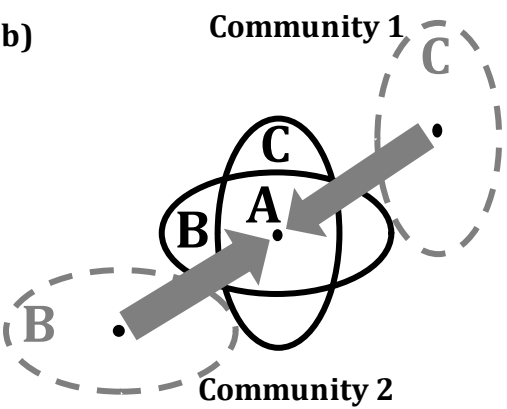

652

653

654

655

656 
657 Appendix S4 After reducing the total number of traits in our analyses down to 7 behavior, 658 morphological, and trophic traits (see Appendix S1), lentic communities' functional beta 659 diversity retained a weak correlation with trophic beta diversity using MRM $\left(R^{2}=0.143, p\right.$ $660<0.01)$ with greater variation exclusively explained by the functional predictor $\left(R^{2}=0.122\right)$ 661 than geographic space $\left(R^{2}=0.010\right)$. Similarly, lotic communities' functional beta diversity 662 had a weak correlation with trophic beta diversity $\left(R^{2}=0.038, p<0.02\right)$ with low variation 663 explained by both geographic space $\left(R^{2}=0.003\right)$ and the functional predictor $\left(R^{2}=0.034\right)$.

664

665 